\title{
A review of extraaxial developmental venous anomalies of the brain involving dural venous flow or sinuses: persistent embryonic sinuses, sinus pericranii, venous varices or aneurysmal malformations, and enlarged emissary veins
}

\author{
Sunil Manjila, MD, ${ }^{1}$ Timothy Bazil, BS, ${ }^{1}$ Matthew Thomas, BS, ${ }^{1}$ Sunithi Mani, MD, ${ }^{2}$ \\ Matthew Kay, MBBS, ${ }^{3}$ and Unni Udayasankar, MD³
}

${ }^{1}$ Department of Neurosurgery, McLaren Bay Region Medical Center, Bay City, Michigan; ${ }^{2}$ Department of Radiology, Christian Medical College, Vellore, Tamil Nadu, India; and ${ }^{3}$ Department of Medical Imaging, University of Arizona College of Medicine, Tucson, Arizona

\begin{abstract}
This paper is a narrative review of extraaxial developmental venous anomalies (eDVAs) of the brain involving dural venous flow or sinuses: persistent embryonic sinuses, sinus pericranii, enlarged emissary veins, and venous varices or aneurysmal malformations. The article highlights the natural history, anatomy, embryology, imaging, clinical implications, and neurosurgical significance of these lesions, which the authors believe represent a continuum, with different entities characterized by distinct embryopathologic features. The indications and surgical management options are discussed for these individual intracranial pathologies with relevant illustrations, and a novel classification is proposed for persistent falcine sinus (PFS). The role of neurointervention and/or microsurgery in specific cases such as sinus pericranii and enlarged emissary veins of the skull is highlighted.

A better understanding of the pathophysiology and developmental anatomy of these lesions can reduce treatment morbidity and mortality. Some patients, including those with vein of Galen malformations (VOGMs), can present with the added systemic morbidity of a high-output cardiac failure. Although VOGM is the most studied and classified of the above-mentioned eDVAs, the authors believe that grouping the former with the other venous anomalies/abnormalities listed above would enable the clinician to convey the exact morphophysiological configuration of these lesions, predict their natural history with respect to evolving venous hypertension or stroke, and extrapolate invaluable insights from VOGM treatment to the treatment of other eDVAs. In recent years, many of these symptomatic venous malformations have been treated with endovascular interventions, although these techniques are still being refined. The authors highlight the broad concept of eDVAs and hope that this work will serve as a basis for future studies investigating the role of evolving focal venous hypertension/global intracranial hypertension and possibilities of fetal surgical intervention in these cases.
\end{abstract}

https://thejns.org/doi/abs/10.3171/2018.5.FOCUS18107

KEYWORDS dural venous sinuses; sinus pericranii; persistent embryonic sinus; vein of Galen malformations; enlarged emissary veins; venous hypertension; embryology; developmental venous anomaly

$\mathrm{M}$ ANY publications over the past few decades have identified the natural history and clinical significance of classic developmental venous anomalies (DVAs) of the brain that are located intraaxially. However, extraaxial DVAs (eDVAs) are discussed in relatively fewer publications, and their various subdivisions are often considered as separate entities, not as part of a spectrum. Classic developmental cranial venous anomalies drain the normal brain parenchyma and are located intraaxially. We believe that persistent embryonic sinuses, sinus pericranii, venous varices or aneurysmal malformations, and enlarged emissary veins comprise a spectrum

ABBREVIATIONS AVF = arteriovenous fistula; $A V M=$ arteriovenous malformation; $D A V F=$ dural AVF; DVA = developmental venous anomaly; $e D V A=$ extraaxial dDVA; MRV = MR venography; PFS = persistent falcine sinus; SP = sinus pericranii; VGAM = vein of Galen aneurysmal malformation; VOGM = vein of Galen malformation. SUBMITTED March 2, 2018. ACCEPTED May 3, 2018. INCLUDE WHEN CITING DOI: 10.3171/2018.5.FOCUS18107. 

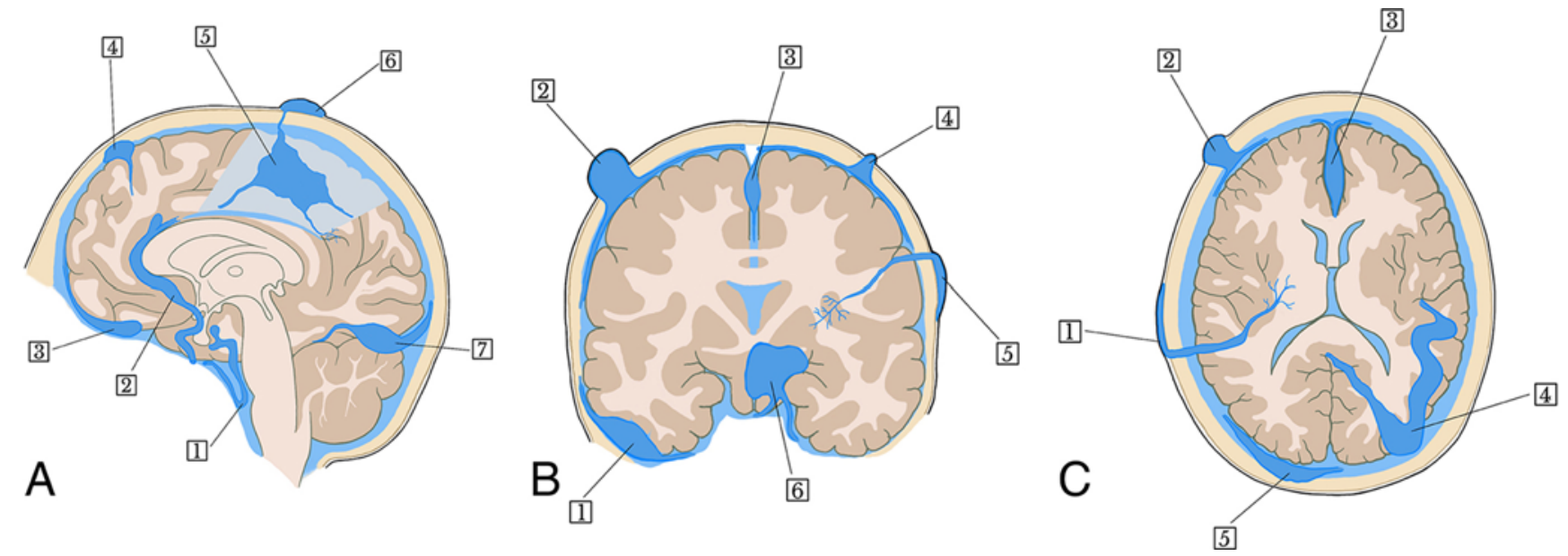

FIG. 1. Artist's rendition of eDVAs. A: Sagittal view showing basal cisternal venous varices associated with sinus thrombosis or AVMs (1); pericallosal varices of above-mentioned etiology (2); basifrontal varices (3); enlarged emissary vein (4); PFS with plexiform architecture (5); SP (6); and elongated/enlarged galenic system (7). B: Coronal view showing middle fossa varices leading to sphenopalatine sinus (1); enlarged (parietal) emissary foramen (2); focal duplication of superior sagittal sinus with PFS (3); SP (4); SP with an intraaxial DVA (5); and tentorial varices occupying the ambient and quadrigeminal cisterns with mass effect on the brainstem (6). C: Axial view showing SP with intraaxial DVA (1); enlarged emissary foramen (2); PFS (3); complex venous varix with parenchymal drainage (4); and intradiploic venous hemangioma/varix (5). Copyright Sunil Manjila. Published with permission.

of eDVAs (Fig. 1). In the eDVAs described in this article, the lesion epicenter is extraaxial, located in the convexity dura, falx, tentorium, etc., even extending to intraosseous and subgaleal sites. Of note, there are some types of sinus pericranii (SP) that are associated with an intraaxial DVA (Fig. 1B-5), and some cisternal venous varices or related arteriovenous pathologies with cortical venous reflux (Fig. 1C-4). These rare subtypes could be considered crossover lesions of the eDVA family, and they require a more detailed physiological and anatomical characterization, like variants in Spetzler-Martin grading of arteriovenous malformations (AVMs).

A better understanding of the pathophysiology and developmental anatomy of eDVAs can reduce treatment morbidity and mortality. In recent years, many of these symptomatic venous malformations have been treated with endovascular interventions, although these techniques are still being refined. In this article, we discuss all the subcategories of eDVAs with reference to their anatomy, embryology, imaging, clinical implications, and neurosurgical significance.

We selected articles from the PubMed database that discussed persistent embryonic sinuses, SP, dural or cisternal varices (often referred to as venous aneurysmal malformations like those encountered in the galenic system), and enlarged emissary veins; these articles were extracted and the data were assessed for quality and optimized search parameters by four reviewers. Although this paper is a narrative review, we have followed most of the PRISMA guidelines for meta-analysis in its preparation.

\section{Persistent Embryonic Sinuses}

Among the persistent embryonic intracranial sinuses, the most common and hence widely studied is the persistent falcine sinus (PFS). Manoj et al..$^{38}$ described how in the early stages of fetal development, when the embryo is around $20 \mathrm{~mm}$ in length, the primitive falx cerebri has been assumed to contain anastomotic venous loops, termed the sagittal plexus. ${ }^{38,69}$ As the embryo develops, the primitive falx cerebri will enclose the sagittal plexus. ${ }^{38}$ Tubbs et al. hypothesized that the sagittal plexus gives rise to the falcine venous plexus. ${ }^{71}$ The dominating venous channel within the sagittal plexus gives rise to the dorsally located superior sagittal sinus, ${ }^{38}$ while the inferior sagittal sinus and straight sinus develop from the ventral portion of the sagittal plexus. ${ }^{38,69,71}$ The smaller channels of the sagittal plexus gradually disappear. ${ }^{69}$ When the occipital pole grows posteriorly, caudal anastomotic loops to the superior sagittal sinus and straight sinus allow for development in the same direction. ${ }^{27,38}$ The sagittal plexus presumably gives rise to the falcine sinus within one of the channels, ${ }^{38,69}$ and in normal development the sagittal plexus involutes before the end of fetal life. ${ }^{38,70}$

Bartels et al. stated that the falcine sinus and the straight sinus arise from the mesenchyme found within the mesencephalic flexure. ${ }^{5}$ Sener emphasized that dysfunction in the mesenchyme may contribute to a PFS and/or absent straight sinus. ${ }^{67}$ Multiple studies have shown that congenital absence of the straight sinus may cause a predilection for recanalization of the falcine sinus to compensate for an atretic sinus. ${ }^{5,17,56,67}$

The existing anatomical classifications of PFS do not account for associated developmental anomalies of the venous system in the brain; there is no definitive radiological criterion for grading PFS that encompasses the architecture and associations of PFS. Ryu stated that it is important that clinicians be cognizant of the congenital anomalies linked to falcine sinuses or straight sinus occlusion. ${ }^{63}$ In the event that a straight sinus occlusion or absence is apparent, it is important to also look for a persisting falcine sinus with a concurrent vein of Galen malformation..$^{56}$ 
TABLE 1. Manjila grading of persistent falcine sinuses

\begin{tabular}{ll}
\hline \multicolumn{1}{c}{ Grade } & \multicolumn{1}{c}{ Description } \\
\hline 1 & Normal falx w/ PFS disconnected from SSS w/ or w/o focal duplication of SSS \\
\hline 2 & Hypoplastic falx cerebri posterior to PFS w/ or w/o hypoplasia of distal SSS \\
\hline 3 & PFS w/ normal falx; deficient straight sinus w/ or w/o dysplastic tentorium cerebelli \\
\hline 4 & PFS w/ hypoplastic falx/SSS associated w/ deficient straight sinus w/ or w/o dysplastic tentorium cerebelli \\
\hline 5 & $\begin{array}{l}\text { PFS grades 1-4 w/ additional neurovascular developmental lesions, like vein of Galen pathologies \& } \\
\text { enlarged parietal emissary veins }\end{array}$ \\
\hline Subtype A & w/ atretic parietal/occipital cephalocele \\
\hline Subtype B & w/o atretic parietal/occipital cephalocele \\
\hline
\end{tabular}

PFS = persistent falcine sinus; SSS = superior sagittal sinus.

Tenting or peaking of the tentorium can occur with any of the grades. Similarly, an enlarged parietal emissary foramen or a focal duplication of the SSS can appear with or without an atretic parietal/occipital cephalocele.

This prompted us to propose a novel grading system for PFS which covered coexisting lesions in a logical stepwise manner (Table 1).

The falcine sinus, a normal venous structure in the fetus located between the dural leaves of the falx cerebri, ${ }^{29}$ is an ascending midline vein that connects the vein of $\mathrm{Ga}$ len and sagittal sinus above the level of the confluence of sinuses and disappears before birth. ${ }^{14}$ Bartels et al. emphasized that the venous plexus in the developing tentorium will influence development of the straight sinus in addition to the sagittal plexus. ${ }^{5}$ A PFS with no additional associated pathology is highly unlikely. ${ }^{29,38,67,70} \mathrm{~A}$ hypoplastic straight sinus or posterior third of the superior sagittal sinus distal to the falcine sinus may influence a PFS, as Manoj et al. have emphasized. ${ }^{38}$ Rhoton $^{60}$ also stated that there is communication between the inferior sagittal sinus and the superior sagittal sinus by way of a venous channel in the falx cerebri. ${ }^{60}$ Tubbs et al. ${ }^{71}$ validated this and classified the falcine venous sinus based on its relationship with the superior sagittal sinus. Type I falcine sinuses have no communication with the superior sagittal sinus and extensive network of inferior sagittal sinus tributaries; type II falcine sinuses have some degree of communication with the superior sagittal sinus; and type III falcine sinuses have considerable communication with the superior sagittal sinus. ${ }^{71}$ These classifications were based on the behavior of the embryonic venous plexus within the falx cerebri, not accounting for adjacent brain changes (such as atretic cephalocele) or associated defects in the straight sinus (Fig. 2).

The newly proposed Manjila classification takes into consideration the pattern of PFS along with associated defects in brain and other dural venous sinuses (straight sinus, superior sagittal sinus); this classification can be used to understand the natural history better and stratify patterns of PFS lesions in syndromic conditions, as they occur with other AVMs, agenesis of the corpus callosum, osteogenesis imperfecta, acrocephalosyndactyly (Apert syndrome), occipital encephaloceles, absent or abnormal tentorium cerebelli, enlarged parietal foramina, and Chiari II malformations. $5,29,57,67,70$

Cephaloceles, also known as "occult," "rudimentary," or "abortive" cephaloceles, are skin-covered cranial dysraphisms caused by "abnormal dysjunction of the mesencephalon," as proposed by McLone and De Leon. ${ }^{42}$ Several groups of authors have stated that cephaloceles are associated with venous anomalies, such as vertical positioning of the embryonic straight sinus, absence of the straight sinus, focal duplication of the superior sagittal sinus, and elongation of the vein of Galen., ${ }^{9,14,42,45,49}$ Brunelle et al. ${ }^{9}$ suggested that venous anomalies are seen when the cephalocele is located above the confluence of sinuses. Occipital cephaloceles are the most common type of cephalocele and typically occur between the lambdoid suture and foramen magnum. ${ }^{39}$ Bartels and colleagues' ${ }^{5}$ study of patients with an occipital encephalocele found an absent straight sinus in all patients as seen on MR venography (MRV). They also observed an alternative drainage pathway of the galenic system through a falcine sinus. ${ }^{5}$ Occipital cephaloceles have a much better clinical prognosis than parietal cephaloceles. ${ }^{77}$ We feel that this is due to involvement of less eloquent dysmorphic brain and fewer draining veins to the posterior third of the sagittal sinus than to the middle third of the sagittal sinus. Reddy et al. ${ }^{57}$ reported a link between prominent parietal foramina and PFS.

\section{Indications and Surgical Management Options}

From a surgical standpoint, if the straight sinus is compromised during surgery, the falcine sinus may have a significant role in alternative venous drainage. ${ }^{26,63}$ This crucial information can help in the management of venous hypertension in selected cases-for example, where a PFS is implicated in pseudotumor cerebri. Conversely, an iatrogenic falcine injury can cause major bleeding and should not be missed on preoperative CTA. ${ }^{63}$ As Tubbs et al. pointed out, there is a rather safe avascular corridor in the falx cerebri for performing a contralateral transfalcine approach to mesial frontoparietal or medial occipital lesions. They observed that most falcine veins are located in the posterior third of the falx cerebri, especially in the inferior two-thirds of the falx in rostrocaudal dimensions. ${ }^{71}$ Caution must be exercised in resection of large falcine meningiomas and techniques required to turn a flap of falx to access the contralateral cerebral hemisphere.

For surgical treatment of a dural arteriovenous fistula (DAVF), resection of the falx cerebri, including the falcine sinus as well as the abnormal falcine plexus, is an appropriate strategy, according to Yamaguchi et al. ${ }^{74}$ Surgi- 

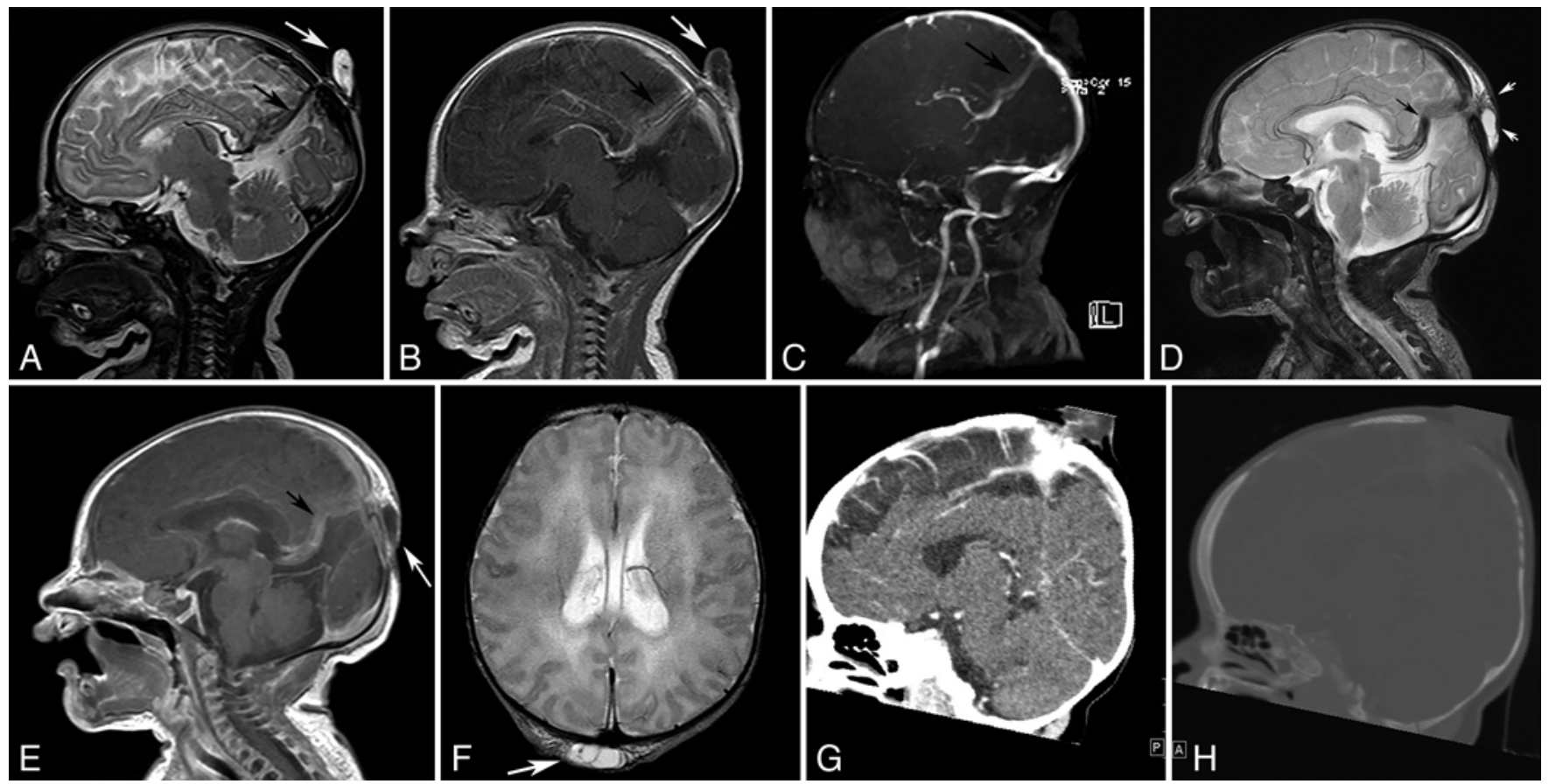

FIG. 2. Persistent falcine sinuses. Demonstration of PFS architecture (Manjila grade $2 A$, a common subtype) with three characteristic architectural patterns: straight or vertical $(A-C)$, angulated $(D-F)$, and plexiform ( $G$ and $H)$. A-C: Atretic parietal cephalocele in a 3-month-old male infant with boggy scalp mass. Sagittal T2-weighted (A) and postcontrast T1-weighted (B) MR images and 3D MR venogram (C) show a T2 hyperintense parietal subgaleal cystic lesion (white arrow) with an associated anomalous vertical falcine vein pointing to the scalp mass (black arrow). D-F: An atretic parietal cephalocele in a 2-month-old female infant with a scalp mass is demonstrated in sagittal T2-weighted (D), sagittal postcontrast T1-weighted (E), and axial T2-weighted (F) images A T2 hyperintense parietal subgaleal cystic lesion (white arrow) can be seen with an associated anomalous vertical falcine vein pointing to the scalp mass (black arrow). $\mathbf{G}$ and $\mathbf{H}$ : The sagittal CT venogram $(\mathrm{G})$ and concurrent $\mathrm{CT}$ bone windows image $(\mathrm{H})$ demonstrate a plexiform pattern of PFS and atretic parietal cephalocele.

cal treatment of atretic cephalocele may be considered if there is reasonable risk for traumatic injury, seizures, and/ or bleeding as well as for cosmetic reasons. In many endoscopic cases, such as interhemispheric approaches, inadvertent parafalcine subdural hematomas are found, likely due to falcine plexus injury.

\section{Sinus Pericranii}

Sinus pericranii (SP) is a rare extradural venous anomaly in which there is an abnormal connection between the extracranial venous system and the intracranial dural sinuses via a connecting diploic vein (Fig. 3). Although the condition is usually asymptomatic, there have also been reports of symptomatic SP causing debilitating headaches, ataxia, nausea, vomiting, hearing loss, epilepsy, bradypnea, and bradycardia. ${ }^{2,24,64}$ Furthermore, SP can cause fatal complications, such as thrombosis, air embolism after trauma, or massive hemorrhage. ${ }^{1,15,51,68}$ SP has also been found to be associated with cases of esophageal atresia, macrocephaly, mental retardation, cerebrofacial arteriovenous metameric syndrome type II (CAMS II), meningocele, craniosynostosis, and other intracranial venous anomalies. $^{22,44,50}$ Although SP is rare, due to the potential severity of the complications, symptoms, and associated syndromes, understanding the etiology, anatomy, presentation, diagnosis, and treatment yields significant value.

\section{Etiopathogenesis}

The comprehension of the possible mechanisms in the formation of SP alerts the clinician as to when to suspect this condition. Several etiologies have been proposed for the SP, some postulated many decades ago, even prior to modern radiological imaging. The best accepted is Mastin's classification, which categorizes the pathogenesis into 3 etiologies: congenital, spontaneous, and traumatic. ${ }^{41}$

Congenital SP can be histologically identified by the presence of vascular endothelium. ${ }^{15}$ This supports Muller's view that congenital hemangiomas are true angiomas coexisting with other vascular anomalies. ${ }^{48}$ The fact that there have been cases of SP in which the patients presented with systemic angiomas, persistent trigeminal arteries, cerebrofacial arteriovenous metameric syndrome type III (CAMS III), facial hemangioma, solitary DVA, vein of Galen aneurysmal malformation, dural sinus malformation, vein of Galen hypoplasia, and intraosseous AVMs supports this congenital theory. ${ }^{7,19,50} \mathrm{SP}$ associated with such other congenital, developmental, or genetic conditions can be explained by errors in the late stages of embryogenesis because the development of brain parenchyma and arterial vasculature precedes vein development. ${ }^{4}$ Congenital SPs have been found in cases of craniosynostosis, such as Apert syndrome, Crouzon syndrome, oxycephaly, and trigonocephaly. ${ }^{43}$ Although the causal relationship of cra- 


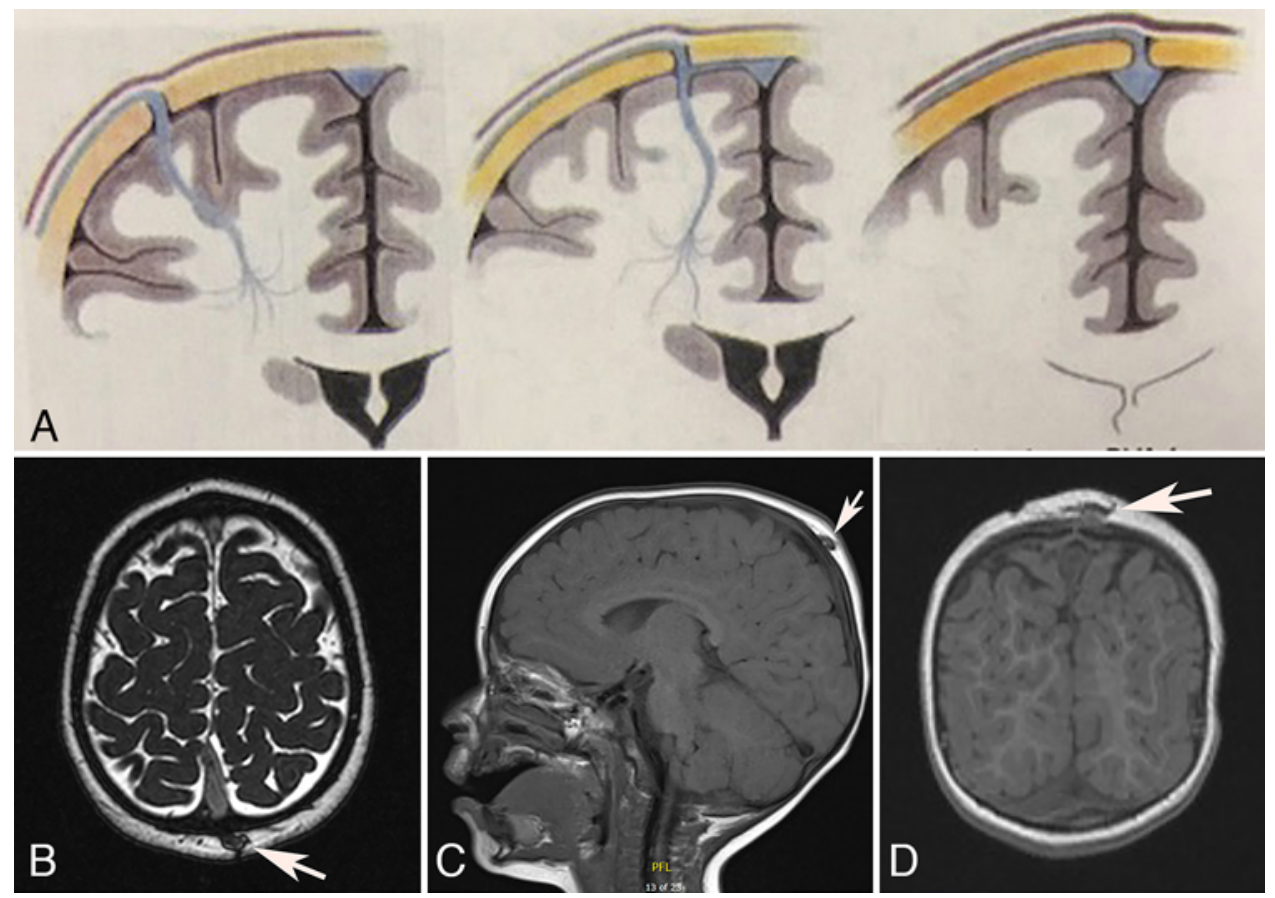

FIG. 3. Sinus pericranii. A: Sinus pericranii classification of three discrete patterns: brain drainage directly into the extracranial SP without accessory drainage into the dural sinus, where embolization is contraindicated (left); brain drainage into both the SP and dural sinus (center), where safety of treatment depends on the relative proportion of sinus drainage; and SP with the transosseous channel connecting the dural sinus to the extracranial vein with normal brain drainage (right), suggestive of safe treatment. Reprinted from Brook AL, Gold MM, Farinhas JM, Goodrich JT, Bello JA: Endovascular transvenous embolization of sinus pericranii. Case report. J Neurosurg Pediatr 3:220-224, 2009. Copyright AANS. Published with permission. B-D: Sinus pericranii in a 2-year-old male infant. Axial CISS (B), sagittal T1-weighted (C), and coronal T1-weighted (D) MR images demonstrate an extracranial left parietal scalp lesion (arrow) near the vertex with an underlying focal calvarial defect.

niosynostosis and SP has not been agreed upon, it can be reasoned that increased intracranial pressure plays a role in affecting venous sinus pressure. Renier and Marchac indicated that intracranial hypertension was observed in $42 \%$ of complex cases of craniosynostosis. ${ }^{59}$ Furthermore, in the absence of overt congenital or traumatic origins, venous hypertension has been suggested as an independent etiology for SP. ${ }^{65}$ This view is supported by the fact that there have been multiple cases of macrocephaly and hydrocephalus coexisting with SP. ${ }^{19,25}$

Both traumatic and spontaneously acquired lesions of SP have a connective tissue endothelial lining, which differentiates them from congenital SP. ${ }^{15}$ Therefore, it can be reasoned that spontaneous SPs are most likely the result of minor trauma that went largely unrecognized. Traumatic SP has been caused by outer table fractures of the cranium, venous sinus tears with epidural hematomas or depressed bone fragments, or disruption of an emissary vein as it leaves the skull. ${ }^{65}$

\section{Clinical Presentation}

The vast majority of SPs present as a nontender compressible and fluctuant subcutaneous mass in the midline of the cranium that increases with Valsalva maneuver. However, in the case of thrombosis, the mass will not be compressible..$^{10}$ Ota et al. reported that SPs are located in the frontal (40\%), parietal (34\%), occipital (18\%), and tem- poral regions (4\%). ${ }^{51}$ Most cases of SP communicate with the superior sagittal sinus. ${ }^{44}$

Although an overwhelming majority of SPs present in the midline of the cranium, cases of trauma and some cases of craniosynostosis can be exceptions. Traumatic SP usually occurs in the area of the trauma. The case report of Sadler et al. presents a traumatic SP in the retromastoid area that communicates with the transverse sinus. ${ }^{64}$ Furthermore, there have been cases of craniosynostosis and coexisting SPs that have occurred in the temporal regions and, in some cases, communicated with the transverse sinus. ${ }^{43}$ However, Mitsukawa et al. reported 7 cases of craniosynostosis with associated midline SP. ${ }^{43}$

\section{Diagnosis and Management}

The diagnosis of SP can be made based on clinical examination and imaging showing an extracranial sinus communicating with an intracranial sinus. Useful investigations include ultrasonography, plain radiography, CT, MRI, and digital subtraction angiography. Ultrasonography will show a venous vessel crossing a hyperechoic cranial vault. ${ }^{19}$ Plain skull radiographs and $\mathrm{CT}$ scans will show bony defects, cortical thinning, and focal bony erosions. ${ }^{78} \mathrm{CT}$ with intravenous contrast will show an enhanced subcutaneous scalp mass corresponding to the SP in relation to the dural sinus. MRI will also show the flow intensity of the SP and the relationship with the adjacent 
intracranial sinus. ${ }^{34}$ Digital subtraction angiography can be used to assess the flow properties of the SP and the adjacent intracranial dural venous sinus. ${ }^{19}$ In a suspected or diagnosed SP, lack of enhancement, or a filling defect, in any intravenous contrast study suggests thrombosis of the SP. ${ }^{73}$ Carpenter et al. found that CT venography was imperative to distinguish intraluminal thrombi from adjacent slow-flowing blood. ${ }^{11}$ We feel that a CT venogram study is better to identify an intraluminal filling defect than MR venogram with contrast administration. The radiological differential diagnosis of subepicranial hygromas, traumatic leptomeningeal cysts, epidermoid/dermoid tumors, encephalocele, and venous cavernoma of the scalp should be also entertained in these cases.

If treatment is considered, definitive vascular imaging using venography should be performed to rule out vascular malformations that mimic SP or any DVAs that coexist with SP, and to assess the intracranial venous dynamics. Asano et al. used delayed 3D CTA to differentiate a subepicranial varix, which lacks intracranial communication with a sinus, from an SP. ${ }^{3}$ Gandolfo et al. proposed that SP is a cutaneous sign of an underlying DVA. Thus, in consideration of surgery, additional investigation of the intracranial venous dynamics is indicated to prevent life-threatening venous congestion and hemorrhage. ${ }^{19}$ Gandolfo et al. used digital subtraction angiography to evaluate drainage patterns of the SP. Specifically, they evaluated any delays in the opacification of scalp vessels; the presence, absence, or malformation of superficial cortical veins in the region of the SP; the drainage pattern of the superior sagittal sinus; and the degree of venous outflow development. ${ }^{19}$ Surgery was contraindicated if the SP was the main venous outflow of the brain, the only collateral pathway to an underlying venous anomaly, or associated with an immature brain outlet, such as a jugular bulb. ${ }^{19}$ In a unique preoperative assessment of SP, Ellis et al. manually occluded the SP and performed angiography to analyze the venous fluid dynamics that would result if the SP were obliterated. ${ }^{18}$ Brook et al. proposed angiographic guidelines for safe surgical or endovascular intervention based on 3 discrete patterns of SP architecture and the relative proportion of sinus drainage (Fig. 3). ${ }^{8}$

Treatment is indicated for SP due to the potential for fatal complications, such as thrombosis, traumatic air embolism, and spontaneous hemorrhage.1,15,51,68 Furthermore, treatment has been indicated in circumstances of debilitating symptomatic SP and aesthetically unpleasing appearances. ${ }^{2,24,64}$ However, there are reported cases of SP resolution with nonsurgical conservative treatment. Carpenter et al. reported resolution of SP in 2 patients after the use of nonsteroidal medications and application of warm compresses. ${ }^{11}$ Additionally, Rozen et al. and Gandolfo et al. have each reported 2 cases of spontaneous resolution of SP.19,62

\section{Microsurgical and Endovascular Approaches}

In the surgical approach to SP, the goal is to resect the exophytic scalp mass and ligate the emissary vein communicating with the intracranial sinus. Craniectomy in the region of the skull with the involved diploic veins followed by cranioplasty has been used. ${ }^{1}$ The removal of the extracranial mass and closure of the transosseous channel using bone wax, absorbable gelatin packing, coagulation, and diamond-drilled bony dust has also been reported in the literature. ${ }^{1}$ However, some studies have reported significant hemorrhage with these surgical methods. ${ }^{7,68}$

A minimally invasive endovascular approach to treatment has been used after angiographic evaluation of the intracranial venous drainage patterns. Brook et al. used angiography to demonstrate independent drainage of a DVA into the superior sagittal sinus without connection to the SP. ${ }^{8}$ Subsequently, the team used an endovascular transvenous approach to embolize the diploic vein of the SP with $N$-butyl cyanoacrylate glue mixed with 1:1 Lipiodol. ${ }^{8} \mathrm{Kes}-$ sler et al. obtained a venogram via direct puncture of the SP followed by microcatheter insertion of two Guglielmi detachable coils and $0.5 \mathrm{ml}$ of acrylic glue injection mixed 4:1 with Lipiodol. ${ }^{28}$ Rangel-Castilla et al. used DynaCT to assess the morphological structure of the SP and digital subtraction angiography to evaluate the venous flow patterns. ${ }^{54}$ Subsequently, endovascular embolization with hydrocoils and ethylene vinyl alcohol copolymer (Onyx, ev3 Inc./Covidien) was used to achieve fast embolization of the diploic vein and minimize the number of coils used. ${ }^{54} \mathrm{With}$ recent advances in endovascular therapy, more SP cases are being treated with nonoperative interventions safely and effectively for indications such as pain relief and cosmesis.

\section{Enlarged Emissary Veins}

Emissary veins are valveless bidirectional veins that connect the extraaxial venous system with the intracranial sinuses of the brain. They serve essential neurophysiological functions such as draining blood from the scalp, equalizing intracranial pressure during cerebral congestion, $7,16,17,40$ temperature regulation, $, 9,23$ and dominant sinus drainage in cases of venous sinus occlusion or vascular malformation. ${ }^{20,31}$ Emissary veins have also been implicated in major pathophysiological processes. Emissary veins can provide conduits for infection in the intracranial sinuses and brain parenchyma. ${ }^{13,16,53,63}$ Enlarged emissary veins have been involved as sources of intraoperative air emboli ${ }^{42}$ and have also been described as forming part of an $\mathrm{AVF}^{21}$ and providing vascular connection to the diploic venous system in the formation of SP. ${ }^{47}$ Along with the developmental, pathophysiological, and neurosurgical implications of emissary veins, a detailed understanding of emissary veins is necessary in the context of venous flow patterns and even inheritance patterns. The inheritance pattern of enlarged parietal foramina is autosomal dominant, raising possibilities of inheritance in eDVAs. ${ }^{72}$

\section{Emissary Vein Anatomy and Neurosurgical Implications}

The size and location of emissary veins may vary between individuals, and not all emissary veins are found in every person. ${ }^{17}$ We used PubMed to identify the most clinically relevant sites of emissary veins. These include, but are not limited to, the condyloid emissary vein, mastoid emissary vein, occipital emissary vein, parietal emissary vein, petrosquamosal sinus, ophthalmic veins, sphenoidal emissary vein, emissary veins of the foramen ovale, internal carotid venous plexus, emissary vein of the foramen cecum, emissary vein of the foramen lacerum, emissary 
veins of the clivus, anterior condylar vein, temporal emissary vein, and superficial petrosal emissary vein. ${ }^{40}$ Emissary veins are named after the region of the skull they are located in. The bidirectional valveless flow of venous blood between the extracranial scalp and intracranial sinuses provides pathways for rapid hematogenous spread of infections. In extensive mastoiditis, the erosion or infiltration of the emissary veins has led to septic emboli and subsequent thrombosis of intracranial venous sinuses, especially the transverse sinus. ${ }^{12}$ Infections of the inferior orbit have also led to septic emboli and subsequent thrombosis of the cavernous sinus via the ophthalmic vein, causing a cavernous sinus syndrome. ${ }^{55}$ Additionally, the mastoid emissary vein has been associated with cavernous sinus infections following a posterior neck abscess. ${ }^{55}$ The petrosquamosal sinus has been associated with the spread of infection or metastasis from the auditory canal in people with inner ear malformations or an underdeveloped jugular vein. ${ }^{35}$ Thus, an inherent risk exists with any neurosurgical procedure to avoid the propagation of septic emboli and subsequent intracranial thrombosis.

Emissary veins also have a wide range of neurosurgical implications. They can serve as landmarks to underlying venous sinuses, ${ }^{36,37,51,55,62}$ be used in endovascular procedures to access intracranial sinuses, ${ }^{28,55}$ and cause hemorrhage with avulsion from the bone in trauma and surgery; ${ }^{36}$ also, improper coagulation can cause extensive thrombosis of intracranial sinuses. ${ }^{15,20}$ In retrosigmoid approaches to the posterior fossa, Mortazavi et al. suggest that emissary veins need to be freed from the skull to avoid avulsion or laceration of underlying sinuses and subsequent hemorrhage or air embolism. ${ }^{47}$ In lateral approaches to the cranial base, sphenoidal emissary veins and veins of the foramen ovale should be appreciated. ${ }^{47}$ The connection of the cavernous sinus with the pterygoid venous plexus may result in complications in epidural procedures due to its connections with the foramen ovale emissary veins and Vesalius emissary veins. ${ }^{26}$ In petrosectomy operations, the location of the petrosquamosal emissary vein should be identified and avoided. Postoperative venous epidural hematomas have been reported to occur from bleeding emissary veins. ${ }^{50}$ Careful consideration should be used in the coagulation of bleeding emissary veins. Temporalis muscle plugs have been shown to be efficient coagulation agents, ${ }^{12}$ while bone wax has the risk of propagating into deeper intracranial sinuses and causing thrombosis and even pulmonary embolism. ${ }^{15,20}$

Emissary veins can also provide essential conduits in complex endovascular neurosurgical procedures. The mastoid emissary vein has been used to gain endovascular access to the transverse sigmoid sinus for the treatment of DAVFs. ${ }^{28,51}$ In a similar endovascular approach, Schipper et al. and many others have used the supraorbital vein to gain access to the ophthalmic vein and subsequently to the cavernous sinus. ${ }^{66}$ Collateral emissary veins have been shown to take the main venous outflow in the removal of cranial base tumors. ${ }^{55}$ Thus, preoperative angiography including a delayed venous phase is necessary to anticipate and avoid a catastrophic thrombosis and postoperative brain infarction.

\section{Development and Anomalies of Emissary Veins}

The early embryonic brain includes superficial, middle, and deep capillary venous plexus layers. ${ }^{47}$ The superficial vessels drain into the external jugular vein and the middle and deep layers drain into the internal jugular vein. ${ }^{47}$ Emissary veins will have residual connections with the superficial and middle layers by the third trimester. ${ }^{35}$ The emissary veins begin most of their development after ballooning of the transverse sinus. ${ }^{44}$ The emissary veins of the hypoglossal canal are the first to develop. ${ }^{58}$ The earliest emissary veins will drain medially into the primitive dural venous sinuses. ${ }^{60}$ The last emissaries to develop are the parietal emissary veins. ${ }^{58}$ The chondrocranium will develop around these vessels and will form respective foramina. ${ }^{60}$ As the jugular sinuses grow, most emissary veins disappear, but some persist and enlarge. ${ }^{47}$ Chauhan et al. proposed that this may be caused by a failure of normal maturation of the sigmoid-jugular sinuses. ${ }^{12}$

Enlarged emissary veins can form from compensatory physiological mechanisms and pathophysiological mechanisms. The absence of valves in emissary veins can result in enlargement during times of increased intracranial pressure. ${ }^{7,16,17,40}$ It has also been proposed that emissary veins regulate the temperature of the brain and dilate in hyperthermia and constrict in hypothermia., ${ }^{9,23}$ Additionally, an enlarged emissary foramen does not always transmit a large emissary vein ${ }^{7}$ (Fig. 4).

Pathological enlargement of emissary veins can result from aberrant connections to arteries or venous varices, ${ }^{19,32,42}$ and enlarged emissary veins have been associated with AVFs and extraaxial venous malformations. Dilated mastoid emissary veins, mastoid canals, anterior condylar emissary veins, and hypoglossal canals have been found with AVFs. ${ }^{32,42}$ In regard to the pathogenesis of DAVFs and enlarged emissary veins, Miyachi et al. proposed that local inflammation near an emissary vein's penetration of the cranium results in enlargement, neovascularization, and subsequent aberrant connections to nearby arteries. ${ }^{44}$ In a case of SP, there has been enlargement of the parietal emissary vein, which served as the connection to the diploic venous system. ${ }^{45}$

Emissary veins can also enlarge secondary to destruction of primary venous outlets in craniofacial syndromes
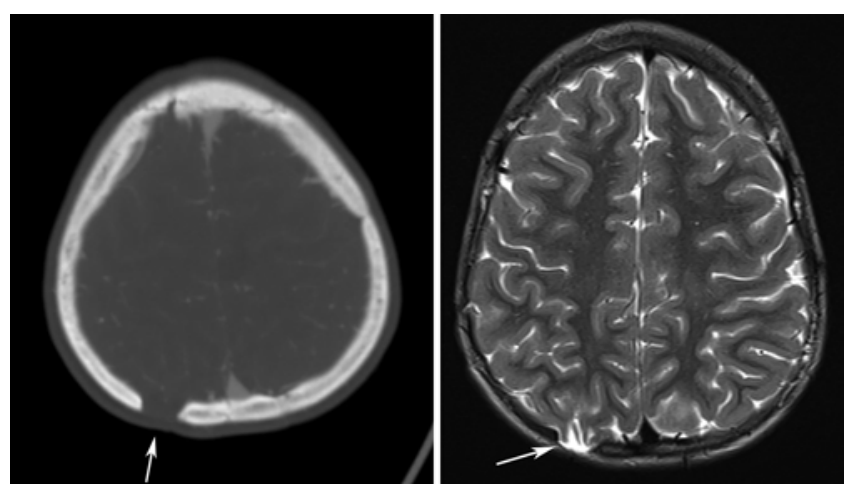

FIG. 4. Enlarged parietal foramen in a 2-week-old female infant. Axial T2-weighted images show a focal defect in the right parietal bone with some extrusion of the meningeal covering and prominence of the CSF space. Of note, no abnormal vascular communication is present. 


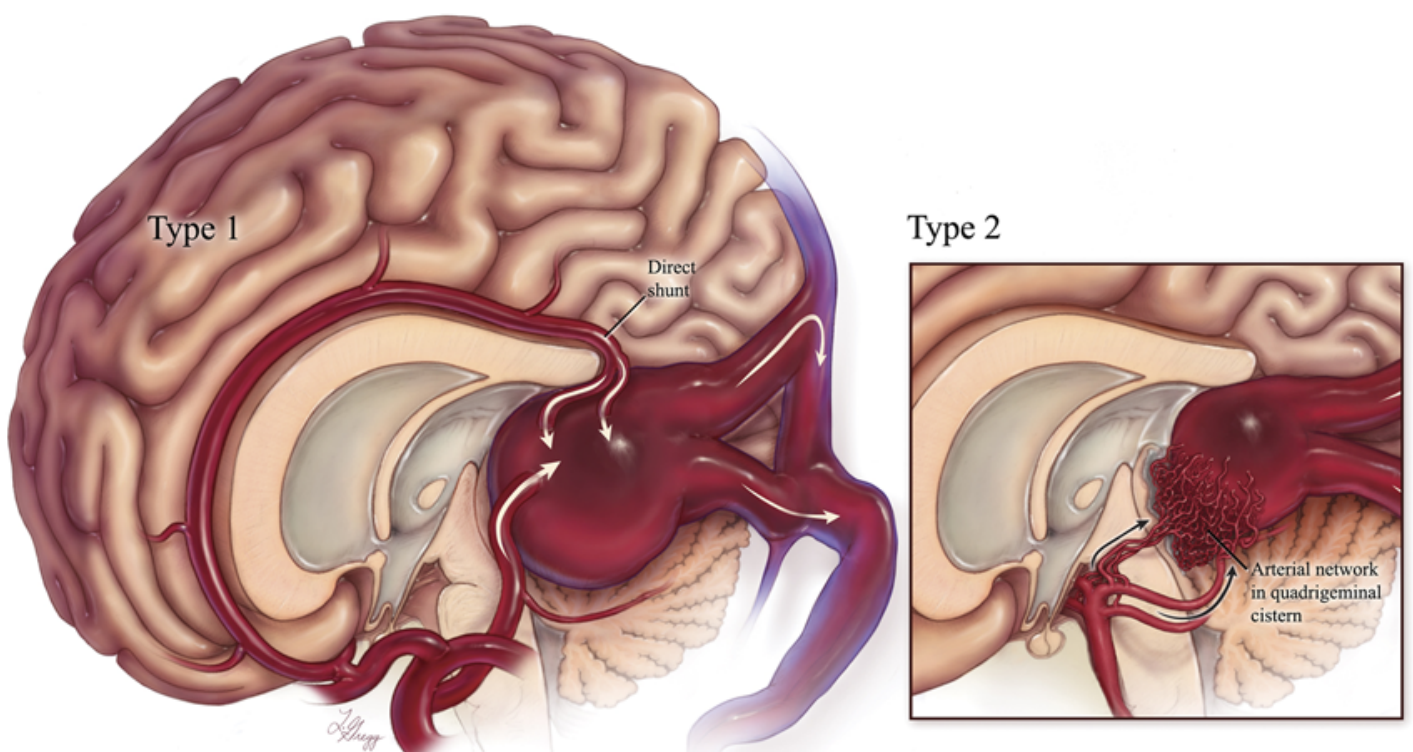

Type 4

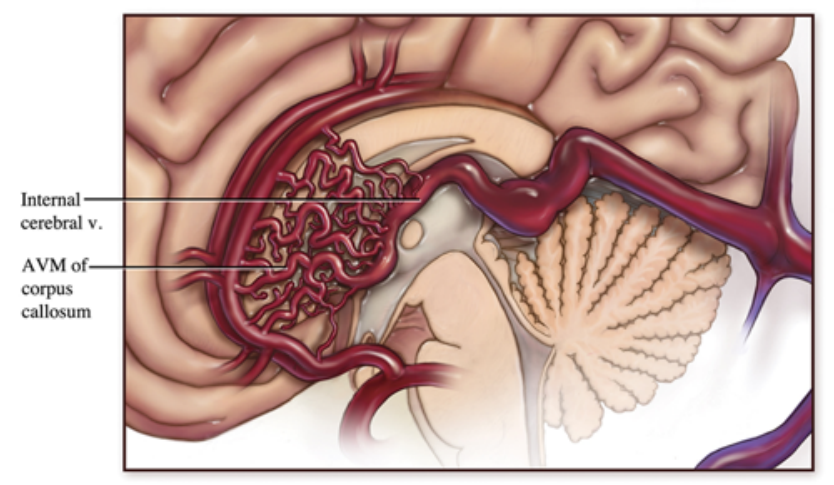

Type 3

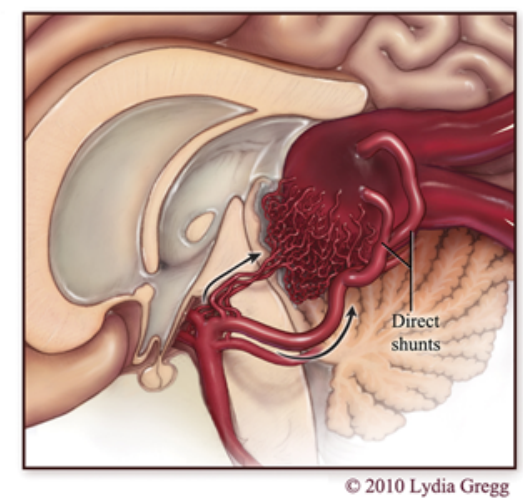

FIG. 5. Classification of vein of Galen malformations. v = vein. Previously published in Pearl M, Gomez J, Gregg L, Gailloud P: Endovascular management of vein of Galen aneurysmal malformations. Influence of the normal drainage on the choice of a treatment strategy. Childs Nerv Syst 26(10):1367-1379, 2010. Image copyright 2010, Lydia Gregg. Image reprinted with permission from Lydia Gregg, MA, CMI, FAMI.

or as a result of increased collateral flow secondary to tumor burden. ${ }^{19,22,35}$ In an anecdotal report, an enlarged condylar emissary vein was found during the removal of a hypoglossal neurinoma. ${ }^{22}$ The coagulation of this channel resulted in a dural venous sinus thrombosis and subsequent cerebellar infarction. ${ }^{22}$ Therefore, it is recommended that a preoperative angiographic evaluation be performed to avoid these surgical complications. Emissary veins can be primarily evaluated on MRI, CT, cerebral angiography, and ultrasonography; any of these modalities could be used for serial follow-up studies, while more invasive catheter-based angiography may be reserved for periprocedural evaluations. ${ }^{7,931}$

\section{Venous Varices and Aneurysmal Malformations}

Venous varices can occur in the brain as a result of dural sinus occlusion or as a part of AVMs or DAVFs. There is an etiologic role of venous hypertension and sinus thrombosis in the former and cortical venous reflux in the latter. However, an intraaxial DVA with a coexistent varix would suggest a causative role for venous hypertension during embryogenesis and changes in posterior projection of the developing brain. The prototypical case for complex extraaxial venous varix remains the vein of Galen malformation (VOGM), often called vein of Galen aneurysmal malformation (VGAM).

\section{Vein of Galen Aneurysmal Malformations}

The vein of Galen is a venous structure within the quadrigeminal cistern formed by the confluence of the internal cerebral veins and the basal veins of Rosenthal. A vein of Galen malformation (VOGM) is a rare vascular anomaly caused by abnormal development of the median prosencephalic vein of Markowski, ${ }^{52,53}$ which is a precursor of the vein of Galen, and VOGMs are thought to develop by the 11th week of gestation..$^{53}$ Raybaud et al. have made significant contributions to the embryological understanding of the vein of Galen. ${ }^{55,56}$ VOGMs, due to the lack of a nidus, are sometimes referred to as arteriovenous fistulas (AVFs), 

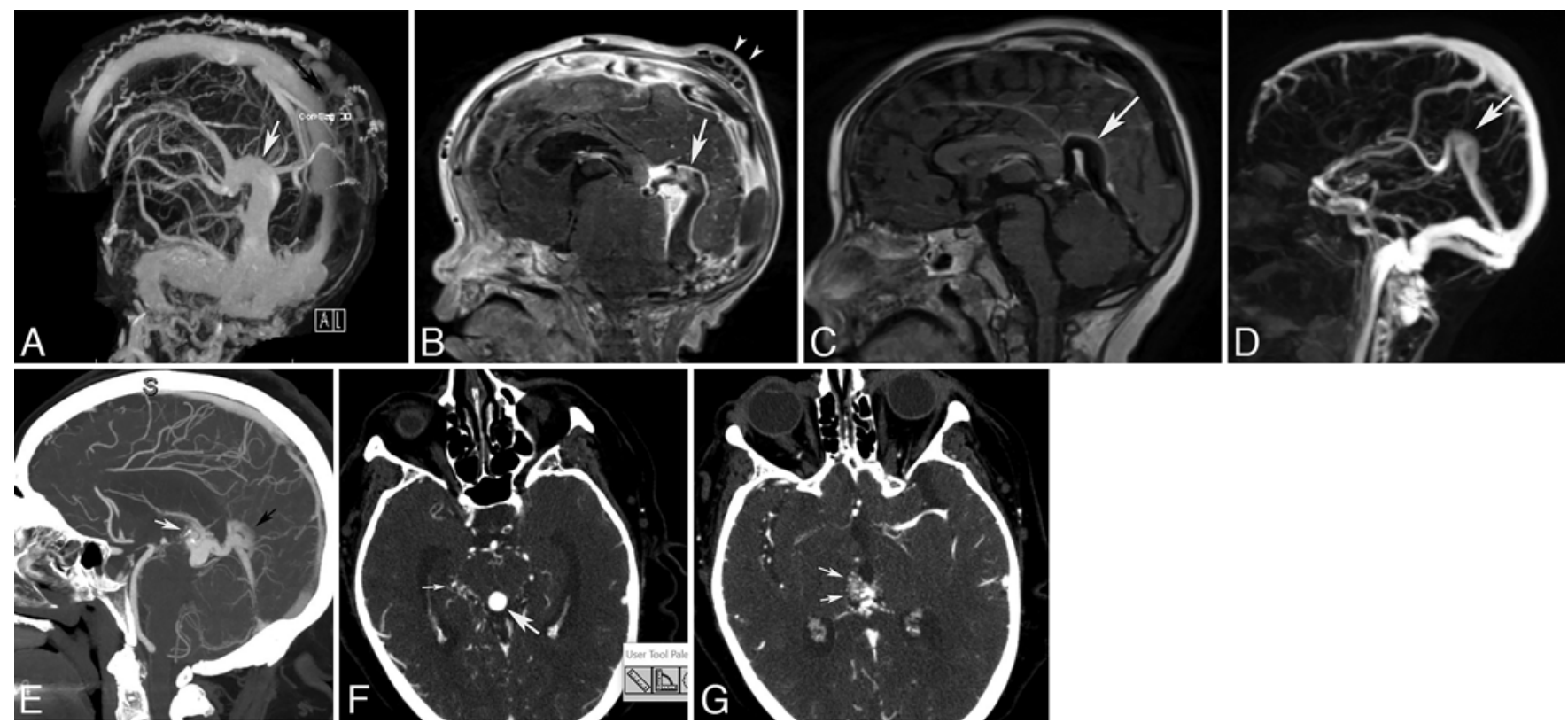

FIG. 6. Radiological images of vein of Galen malformations. A and B: High-flow vein of Galen malformation (Yaşargil type III). $3 D$ reformatted postcontrast MRV image (A) and postcontrast sagittal T1-weighted MR image (B) showing a massively enlarged vein of Galen (white arrow), the straight sinus, and bilateral transverse sinuses. Also note the abnormal communication between the intracranial and extracranial venous vessels through an enlarged open parietal foramen (black arrow) leading to multiple dilated scalp veins (arrowheads). C and D: Slow-flow variety (Yaşargil type II) vein of Galen malformation. Sagittal postcontrast T1-weighted MR image (C) and 3D maximum-intensity projection postcontrast MRV image (D) showing a prominent vein of Galen (arrow) with a few prominent flow voids near the bilateral posterior cingulate gyri (not shown). E-G: Right medial thalamic parenchymal AVM with drainage to the vein of Galen (Yaşargil type IV). Sagittal maximum-intensity projection image (E) demonstrates a dilated vein of Galen (black arrow) draining a right thalamic AVM (white arrow). Axial postcontrast CTA image through the thalami (F) shows the right thalamic AVM (arrows). An enlarged vein of Galen (large arrow) and multiple feeder vessels in the perimesencephalic cistern (small arrows) are well demonstrated on an axial postcontrast CTA image (G) through the midbrain.

with the first vein of Galen arteriovenous malformations (VGAMs) being reported by Steinheil..$^{53}$ The term VGAM will be used for the remainder of this discussion.

VGAMs typically occur in young children and can be diagnosed in utero by ultrasound and/or fetal MRI ${ }^{53}$ With respect to the chronological development of VGAMs, there is debate as to the timing; they have been described as arising between the 6th and 8th to 11th weeks of gestation. ${ }^{52,53,56}$ Venous drainage from VGAMs is variable, as there are a number of potential outflow pathways, which is also dependent on the venous anatomy that is or is not present at that stage of development. ${ }^{46}$ Examples include a normal straight sinus, a hypoplastic straight sinus, an absent straight sinus, and/or a persistent falcine sinus (PFS). The shunting associated with VGAMs is associated with high-output cardiac failure during the neonatal period. . $^{61,75}$ Symptomatic VGAMs in neonates are nearly always fatal if left untreated. ${ }^{6}$ Positive outcomes are most likely to occur if endovascular therapy is initiated in a timely manner, ${ }^{30,53}$ as Lasjaunias has emphasized, and a delay may also cause disruption in cerebrospinal fluid flow. ${ }^{30,53}$

Yaşargil, ${ }^{76}$ Litvak et al., ${ }^{36}$ and Lasjaunias and colleagues $^{30-32}$ established various VGAM classifications as shown in Table 2 and Fig. 5. Litvak et al. ${ }^{36}$ described the first classification system in 1960, but it lost popularity once newer classification systems were introduced. The newer VGAM classification systems-the Lasjaunias classification ${ }^{6}$ and the Yaşargil classification ${ }^{7}$ - are broadly based on the origin (and number) of the feeding arteries and the location of the arteriovenous communication and are useful due to their prognostic and/or treatment implications. Endovascular embolization is the current standard of care for the treatment of VGAMs. ${ }^{31,33,46,75}$ While transvenous coil embolization, glue embolization, and the combination of the two are becoming popular treatment options, transarterial embolization is often preferred. ${ }^{53}$ The goal of endovascular therapy is to occlude the vessels that supply the arteriovenous shunt or to embolize vessels that drain the lesion itself. ${ }^{52}$ The treatment strategy and outcome depend primarily on the venous anatomy, ${ }^{52}$ the classification of the lesion, and the presence or absence of cardiac failure (Fig. 6).

We would like to point out that eDVAs that present as cisternal venous varices do not have a natural history similar to that of venous angiomas or intraaxial DVAs. In contrast to venous angiomas (associated with intraaxial DVAs), which are dilated veins of developmental origin, the intraaxial DVA complexes can cause obstructive hydrocephalus in certain cases. Venous angiomas are rarely symptomatic in intraaxial locations, although they can cause hemorrhages and infarctions in some of these cases. Nonetheless, there are no indications for surgical interventions in venous angiomas. Hydrocephalus resulting from an eDVA is seldom reported. 
TABLE 2. Classifications of vein of Galen aneurysmal malformations

\begin{tabular}{|c|c|}
\hline Classification & Description \\
\hline \multicolumn{2}{|l|}{ Litvak et al., 1960} \\
\hline Category A & Aneurysms of the vein of Galen \\
\hline Category B & Racemose configuration of blood vessels in cerebral structures \\
\hline Category C & Transitional types of midline AV shunts \\
\hline \multicolumn{2}{|l|}{ Lasjaunias, 1997} \\
\hline Type I & Choroidal \\
\hline Type II & Mural \\
\hline \multicolumn{2}{|l|}{ Yaşargil, 1988} \\
\hline Type I & AVF btwn leptomeningeal arteries \& feeders from $\mathrm{P}_{3}$, segments of PCAs, \& vein of Galen \\
\hline Type II & Feeders from thalamo-perforating vessels \& from $P_{1}$ and $P_{2}$ segments of PCAs \\
\hline Type III & Combination of types I \& || \\
\hline \multicolumn{2}{|l|}{ Type IV } \\
\hline IV A & Aneurysmal dilation of vein of Galen due to shunting from an adjacent thalamic AVM \\
\hline IV B & Aneurysmal dilation of vein of Galen due to shunting from an adjacent mesencephalic AVM \\
\hline IV C & $\begin{array}{l}\text { Thalamomesencephalic or mesodiencephalic plexiform malformation \& a separate cisternal AVF } \\
\text { adjacent to the vein of Galen }\end{array}$ \\
\hline \multicolumn{2}{|c|}{ Secondary enlargement of vein of Galen } \\
\hline Vein of Galen dilation & $\begin{array}{l}\text { Malformations that drain pial or dural shunts into true vein of Galen or tributary associated w/ } \\
\text { dilation of vein of Galen }\end{array}$ \\
\hline Vein of Galen varix & Dilation of vein of Galen w/o AV shunt \\
\hline
\end{tabular}

$\mathrm{AV}=$ arteriovenous; $\mathrm{PCA}=$ posterior cerebral artery.

\section{Conclusions}

We have provided a contemporary update on the various extraaxial developmental cranial venous anomalies with relevant classifications and clinical implications. Persistent embryonic sinuses, sinus pericranii, venous varices or aneurysmal malformations, and enlarged emissary veins, considered as a continuum, form the spectrum of extraaxial DVAs (eDVAs). Symptomatic eDVAs are being treated with endovascular interventions alone or in combination with microsurgery, although these techniques are still being refined. Basic knowledge of developmental anatomy and natural history of these lesions offers an ideal research substrate for future studies looking at the role of evolving venous hypertension/intracranial hypertension and possibilities of fetal surgical intervention in these cases.

\section{Acknowledgments}

We sincerely thank Isaac Abrahamson, Bay City, Michigan, for his excellent illustrations (Fig. 1A-C) used in this manuscript.

We extend our gratitude to Lydia Gregg, assistant professor and medical illustrator at the John Hopkins University School of Medicine, for allowing us to reprint the illustration in Fig. 5. We also wholeheartedly appreciate the assistance of Ms. Patti Wesenick, librarian at McLaren Bay Region Medical Center, Bay City, Michigan, in the preparation of this manuscript.

\section{References}

1. Alexander EJ, Ball MR: Sinus pericranii, in Wilkins RH, Rengachary SS (eds): Neurosurgery Update II: Vascular, Spinal, Pediatric, and Functional Neurosurgery. New York: McGraw-Hill, 1991, pp 70-72

2. Anegawa S, Hayashi T, Torigoe R, Nakagawa S, Ogasawara
T: Sinus pericranii with severe symptom due to transient disorder of venous return-case report. Neurol Med Chir (Tokyo) 31:287-289, 1991

3. Asano K, Sobata E, Kubo O: Subepicranial varix mimicking sinus pericranii: usefulness of three-dimensional computed tomography angiography and bone window computed tomography-case report. Neurol Med Chir (Tokyo) 40:467-471, 2000

4. Barkovich AJ, Chuang SH, Norman D: MR of neuronal migration anomalies. AJR Am J Roentgenol 150:179-187, 1988

5. Bartels RH, Merx JL, van Overbeeke JJ: Falcine sinus and occipital encephalocele: a magnetic resonance venography study. J Neurosurg 89:738-741, 1998

6. Berenstein A, Fifi JT, Niimi Y, Presti S, Ortiz R, Ghatan S, et al: Vein of Galen malformations in neonates: new management paradigms for improving outcomes. Neurosurgery 70:1207-1214, 2012

7. Bollar A, Allut AG, Prieto A, Gelabert M, Becerra E: Sinus pericranii: radiological and etiopathological considerations. Case report. J Neurosurg 77:469-472, 1992

8. Brook AL, Gold MM, Farinhas JM, Goodrich JT, Bello JA: Endovascular transvenous embolization of sinus pericranii. Case report. J Neurosurg Pediatr 3:220-224, 2009

9. Brunelle F, Baraton J, Renier D, Teillac D, Simon I, Sonigo $\mathrm{P}$, et al: Intracranial venous anomalies associated with atretic cephalocoeles. Pediatr Radiol 30:743-747, 2000

10. Cabanac M, Brinnel H: Blood flow in the emissary veins of the human head during hyperthermia. Eur J Appl Physiol Occup Physiol 54:172-176, 1985

11. Carpenter JS, Rosen CL, Bailes JE, Gailloud P: Sinus pericranii: clinical and imaging findings in two cases of spontaneous partial thrombosis. AJNR Am J Neuroradiol 25:121-125, 2004

12. Chauhan NS, Sharma YP, Bhagra T, Sud B: Persistence of multiple emissary veins of posterior fossa with unusual 
origin of left petrosquamosal sinus from mastoid emissary. Surg Radiol Anat 33:827-831, 2011

13. Cheatle A: The mastoid emissary vein and its surgical importance. Proc R Soc Med 18 (Otol Sect):29-34, 1925

14. Cho J, Kim MY, Roh HG, Moon WJ: MR images of spontaneously involuted atretic cephalocele concomitant with persistent falcine sinus in an adult. J Korean Soc Magn Reson Med 10:117-120, 2006

15. Cohn I: Sinus pericranii: report of a case, review of literature. Surg Gynecol Obstet 42:614-624, 1926

16. Crocker M, Nesbitt A, Rich P, Bell B: Symptomatic venous sinus thrombosis following bone wax application to emissary veins. Br J Neurosurg 22:798-800, 2008

17. Curé JK, Van Tassel P, Smith MT: Normal and variant anatomy of the dural venous sinuses. Semin Ultrasound CT MR 15:499-519, 1994

18. Ellis JA, Mejia Munne JC, Feldstein NA, Meyers PM: Determination of sinus pericranii resectability by external compression during angiography: technical note. J Neurosurg Pediatr 16:1-5, 2015

19. Gandolfo C, Krings T, Alvarez H, Ozanne A, Schaaf M, Baccin CE, et al: Sinus pericranii: diagnostic and therapeutic considerations in 15 patients. Neuroradiology 49:505-514, 2007

20. Garza-Mercado R: Extradural hematoma of the posterior cranial fossa. Report of seven cases with survival. J Neurosurg 59:664-672, 1983

21. Hadeishi H, Yasui N, Suzuki A: Mastoid canal and migrated bone wax in the sigmoid sinus: technical report. Neurosurgery 36:1220-1224, 1995

22. Hayakawa I, Fujiwara K, Sasaki A, Hirata T, Yanagibashi K, Tsuchida T: [Spontaneous regression of sinus pericranii-report of a case (author's transl).] No Shinkei Geka 6:91-95, 1978 (Jpn)

23. Hoshi M, Yoshida K, Ogawa K, Kawase T: Hypoglossal neurinoma-two case reports. Neurol Med Chir (Tokyo) 40:489-493, 2000

24. Inci S, Turgut M, Saygi S, Gurcay O: Sinus pericranii associated with epilepsy. Turk Neurosurg 6:21-24, 1996

25. Kamble RB, Venkataramana NK, Naik L, Shailesh, Shetty $\mathrm{R}$ : Sinus pericranii presenting with macrocephaly and mental retardation. J Pediatr Neurosci 5:39-41, 2010

26. Kanno T, Sugiishi N, Kasama A: Surgical ablation of veins and sinuses: safety and risk, in Hakuba A (ed): Surgery of the Intracranial Venous System. Tokyo: Springer, 1996, pp $116-120$

27. Kesava PP: Recanalization of the falcine sinus after venous sinus thrombosis. AJNR Am J Neuroradiol 17:1646-1648, 1996

28. Kessler IM, Esmanhoto B, Riva R, Mounayer C: Endovascular transvenous embolization combined with direct punction of the sinus pericranii. A case report. Interv Neuroradiol 15:429-434, 2009

29. Kim MS, Lee GJ: Two cases with persistent falcine sinus as congenital variation. J Korean Neurosurg Soc 48:82-84, 2010

30. Lasjaunias P: Vein of Galen aneurysmal malformation, in Vascular Diseases in Neonates, Infants, and Children. Berlin: Springer, 1997, pp 67-202

31. Lasjaunias P, Hui F, Zerah M, Garcia-Monaco R, Malherbe V, Rodesch G, et al: Cerebral arteriovenous malformations in children. Management of 179 consecutive cases and review of the literature. Childs Nerv Syst 11:66-79, 1995

32. Lasjaunias P, Terbrugge K, Piske R, Lopez Ibor L, Manelfe C: [Dilatation of the vein of Galen. Anatomoclinical forms and endovascular treatment apropos of 14 cases explored and/ or treated between 1983 and 1986.] Neurochirurgie 33:315333, 1987 (Fr)

33. Lasjaunias PL, Chng SM, Sachet M, Alvarez H, Rodesch G, Garcia-Monaco R: The management of vein of Galen aneu- rysmal malformations. Neurosurgery 59 (5 Suppl 3):S184S194, S3-S13, 2006

34. Layton KF: Embolization of an intracranial dural arteriovenous fistula using ultrasound-guided puncture of a pericranial venous pouch. Proc Bayl Univ Med Cent 22:332-334, 2009

35. Lee C, Lee Y, Lee J, Lee H, Ryu K, Dong K: Sinus pericranii: a case report and the literature review. Korean J Cerebrovasc Surg 11:174-178, 2009

36. Litvak J, Yahr MD, Ransohoff J: Aneurysms of the great vein of Galen and midline cerebral arteriovenous anomalies. J Neurosurg 17:945-954, 1960

37. Louis RG Jr, Loukas M, Wartmann CT, Tubbs RS, Apaydin N, Gupta AA, et al: Clinical anatomy of the mastoid and occipital emissary veins in a large series. Surg Radiol Anat 31:139-144, 2009

38. Manoj KS, Krishnamoorthy T, Thomas B, Kapilamoorthy TR: An incidental persistent falcine sinus with dominant straight sinus and hypoplastic distal superior sagittal sinus. Pediatr Radiol 36:65-67, 2006

39. Marín-Padilla M: Cephalic axial skeletal-neural dysraphic disorders: embryology and pathology. Can J Neurol Sci 18:153-169, 1991

40. Marsot-Dupuch K, Gayet-Delacroix M, Elmaleh-Bergès M, Bonneville F, Lasjaunias P: The petrosquamosal sinus: CT and MR findings of a rare emissary vein. AJNR Am J Neuroradiol 22:1186-1193, 2001

41. Mastin WM: IV. Venous blood-tumors of cranium communicating with superior longitudinal sinus. Ann Surg 1:324340,1885

42. McLone DG, De Leon G: Atretic encephalocele. Pediatr Neurosurg 28:326, 1998

43. Mitsukawa N, Satoh K, Hayashi T, Furukawa Y, Suse T, Uemura T, et al: Sinus pericranii associated with craniosynostosis. J Craniofac Surg 18:78-84, 2007

44. Miyachi S, Izumi T, Matsubara N, Naito T, Haraguchi K, Wakabayashi T: Mechanism of the formation of dural arteriovenous fistula: the role of the emissary vein. Interv Neuroradiol 17:195-202, 2011

45. Morioka T, Hashiguchi K, Samura K, Yoshida F, Miyagi Y, Yoshiura T, et al: Detailed anatomy of intracranial venous anomalies associated with atretic parietal cephaloceles revealed by high-resolution 3D-CISS and high-field T2-weighted reversed MR images. Childs Nerv Syst 25:309-315, 2009

46. Mortazavi MM, Griessenauer CJ, Foreman P, Bavarsad Shahripour R, Shoja MM, Rozzelle CJ, et al: Vein of Galen aneurysmal malformations: critical analysis of the literature with proposal of a new classification system. J Neurosurg Pediatr 12:293-306, 2013

47. Mortazavi MM, Tubbs RS, Riech S, Verma K, Shoja MM, Zurada A, et al: Anatomy and pathology of the cranial emissary veins: a review with surgical implications. Neurosurgery 70:1312-1319, 2012

48. Muller A: Ueber Sinus pericranii. Berl Klin Wchnschr 49:1372-1376, 1912

49. Murakami N, Morioka T, Kawamura N, Suzuki SO, Kira R: Venous anomaly analogous to vertical embryonic positioning of the straight sinus associated with atretic cephalocele at the suboccipital region. Childs Nerv Syst 33:179-182, 2017

50. Nakasu Y, Nakasu S, Minouchi K, Handa J: Multiple sinus pericranii with systemic angiomas: case report. Surg Neurol 39:41-45, 1993

51. Ota T, Waga S, Handa H, Nishimura S, Mitani T: Sinus pericranii. J Neurosurg 42:704-712, 1975

52. Pearl M, Gomez J, Gregg L, Gailloud P: Endovascular management of vein of Galen aneurysmal malformations. Influence of the normal venous drainage on the choice of a treatment strategy. Childs Nerv Syst 26:1367-1379, 2010

53. Puvabanditsin S, Mehta R, Palomares K, Gengel N, Da Silva $\mathrm{CF}$, Roychowdhury S, et al: Vein of Galen malformation in a 
neonate: a case report and review of endovascular management. World J Clin Pediatr 6:103-109, 2017

54. Rangel-Castilla L, Krishna C, Klucznik R, Diaz O: Endovascular embolization with Onyx in the management of sinus pericranii: a case report. Neurosurg Focus 27(5):E13, 2009

55. Raybaud CA, Strother CM: Persisting abnormal embryonic vessels in intracranial arteriovenous malformations. Acta Radiol Suppl 369:136-138, 1986

56. Raybaud CA, Strother CM, Hald JK: Aneurysms of the vein of Galen: embryonic considerations and anatomical features relating to the pathogenesis of the malformation. Neuroradiology 31:109-128, 1989

57. Reddy AT, Hedlund GL, Percy AK: Enlarged parietal foramina: association with cerebral venous and cortical anomalies. Neurology 54:1175-1178, 2000

58. Reis CV, Deshmukh V, Zabramski JM, Crusius M, Desmukh P, Spetzler RF, et al: Anatomy of the mastoid emissary vein and venous system of the posterior neck region: neurosurgical implications. Neurosurgery 61 (5 Suppl 2):193-201, 2007

59. Renier D, Marchac D: Craniofacial surgery for craniosynostosis: functional and morphological results. Ann Acad Med Singapore 17:415-426, 1988

60. Rhoton AL: Rhoton Cranial Anatomy and Surgical Approaches. Schaumburg, IL: Congress of Neurological Surgeons, 2003, pp 187-233

61. Rodesch G, Hui F, Alvarez H, Tanaka A, Lasjaunias P: Prognosis of antenatally diagnosed vein of Galen aneurysmal malformations. Childs Nerv Syst 10:79-83, 1994

62. Rozen WM, Joseph S, Lo PA: Spontaneous involution of two sinus pericranii-a unique case and review of the literature. $\mathbf{J}$ Clin Neurosci 15:833-835, 2008

63. Ryu CW: Persistent falcine sinus: is it really rare? AJNR Am J Neuroradiol 31:367-369, 2010

64. Sadler LR, Tarr RW, Jungreis CA, Sekhar L: Sinus pericranii: CT and MR findings. J Comput Assist Tomogr 14:124-127, 1990

65. Sakai K, Namba K, Meguro T, Mandai S, Gohda Y, Sakurai $\mathrm{M}$, et al: Sinus pericranii associated with a cerebellar venous angioma-case report. Neurol Med Chir (Tokyo) 37:464467, 1997

66. Schipper J, Hoffmann T, Wagenmann M, Stummer W, Knapp F, Klenzner T, et al: [Significance of emissary veins in surgical treatment of temporal paragangliomas.] HNO 57:146152,2009 (Ger)

67. Sener RN: Association of persistent falcine sinus with different clinicoradiologic conditions: MR imaging and MR angiography. Comput Med Imaging Graph 24:343-348, 2000

68. Spektor S, Weinberger G, Constantini S, Gomori JM, BeniAdani L: Giant lateral sinus pericranii. Case report. J Neurosurg 88:145-147, 1998
69. Streeter G: Development of venous sinus of dura mater in human embryo. Am J Anat 18:145-191, 1915

70. Strub WM, Leach JL, Tomsick TA: Persistent falcine sinus in an adult: demonstration by MR venography. AJNR Am J Neuroradiol 26:750-751, 2005

71. Tubbs RS, Loukas M, Louis RG Jr, Shoja MM, AcakpoSatchivi L, Blount JP, et al: Anatomy of the falcine venous plexus. J Neurosurg 107:155-157, 2007

72. Wilkie AOM, Mavrogiannis LA: Enlarged parietal foramina, in Adam MP, Ardinger HH, Pagon RA, et al (eds): GeneReviews. Seattle: University of Washington, 2004

73. Witrak BJ, Davis PC, Hoffman JC Jr: Sinus pericranii. A case report. Pediatr Radiol 16:55-56, 1986

74. Yamaguchi T, Higaki A, Yokota H, Mashiko T, Oguro K: A case of dural arteriovenous fistula in the falx cerebri: case report and review of the literature. NMC Case Rep J 3:67-70, 2016

75. Yan J, Wen J, Gopaul R, Zhang CY, Xiao SW: Outcome and complications of endovascular embolization for vein of Galen malformations: a systematic review and meta-analysis. J Neurosurg 123:872-890, 2015

76. Yaşargil MG: AVM of vein of Galen region, in: Microneurosurgery: AVM of the Brain, Clinical Considerations, General and Special Operative Techniques, Surgical Results, Nonoperated Cases, Cavernous and Venous Angiomas, Neuroanesthesia. Stuttgart: Thieme, 1988, Vol IIIB, pp 323-354

77. Yokota A, Kajiwara H, Kohchi M, Fuwa I, Wada H: Parietal cephalocele: clinical importance of its atretic form and associated malformations. J Neurosurg 69:545-551, 1988

78. Yun D, Kim H, Chou S, Kim S: Sinus pericranii-case report. Korean J Cerebrovasc Surg 13:75-79, 2011

\section{Disclosures}

The authors report no conflict of interest concerning the materials or methods used in this study or the findings specified in this paper.

\section{Author Contributions}

Conception and design: Manjila, Bazil, Thomas, Kay. Acquisition of data: all authors. Analysis and interpretation of data: all authors. Drafting the article: Manjila, Bazil, Thomas. Critically revising the article: Manjila, Bazil, Thomas. Reviewed submitted version of manuscript: Manjila, Bazil, Thomas. Administrative/ technical/material support: Kay. Study supervision: Bazil.

\section{Correspondence}

Sunil Manjila: McLaren Bay Region Hospital, Bay City, MI. sunil. manjila@gmail.com. 